\title{
The Embryotoxicity of Gossypol
}

\author{
ALLAN R. BEAUDOIN \\ Department of Anatomy and Cell Biology, University of Michigan, \\ Ann Arbor, Michigan 48109-0010
}

\begin{abstract}
In utero development was analyzed in pregnancies that resulted from matings between gossypol-treated male rats and untreated female rats and in pregnancies in which gossypol was administered to the pregnant rat only. Gossypol treatment of males had no effect on the outcome of pregnancy. There was no significant effect on resorption, fetal growth, or malformation rate. Similarly, gossypol administered to pregnant dams at stages during organogenesis had no observable effect on pregnancy. Under the conditions of this experiment, gossypol administered to either the breeding male rat or the pregnant female rat had no demonstrable adverse effect on development in utero.
\end{abstract}

The antifertility effect of gossypol in males was first reported in China (National Coordinating Committee on Male Antifertility Agents, '78). Subsequently, antifertility studies have been conducted in several mammals, including rats (Chang et al., '80; Hadley et al., '81; Hahn et al., '81; Weinbauer et al., '82), mice (Hahn et al., ' 81 ), hamsters (Chang et al., ' 80 ; Hahn et al., ' 81 ; Saksena and Salmonsen, '82), rabbits (Chang et al., '80; Saksena et al., '81), and monkeys (Shandilya et al., '82).

Gossypol has several effects on spermatozoa: It causes their deterioration, culminating in the loss of motility and often a separation of sperm head from sperm tail. It causes abnormalities in the mitochondrial sheath of the midpiece (Bozek et al., ' 81 ; Hoffer, '82; Oko and Hrudka, '82). It interferes with biochemical events, e.g., uncouples oxidative phosphorylation and reduces ATP concentration in vivo and in vitro (Ke and Tso, '82; Tso et al., ' 82 ), inhibits the activity of various enzymes (Kalla and Vasudev, ' 81 ; Kennedy et al., '83; Lee et al., '82; Tso and Lee, '82), and reduces steroidogenesis (Hadley et al., '81; Lin et al., '81; Saksena and Salmonsen, '82).

In spite of rather extensive studies on the effects of gossypol on the morphology and biochemistry of the testes and spermatozoa, relatively little information is available about in utero development following fertilization with sperm from males undergoing gossypol treatment. This study was designed to obtain such information. The effect of gos- sypol on the pregnant rat was also investigated.

\section{METHODS}

Sprague-Dawley rats, purchased from Charles River (Kingston, NY) were used in this study. The animal rooms were maintained at a relatively constant temperature $\left(72^{\circ} \mathrm{F}\right)$ with a 12 -hour light/dark cycle. The rats were fed Purina Rodent Lab Chow 5001 and water ad libitum.

Gossypol acetic acid (95\% pure) was obtained from Dr. Sheldon Segal of the Population Division, Rockefeller Foundation, New York. Gossypol was administered as its acetic acid or as gossypol prepared from its acetic acid according to the procedure described by Pons et al. ('59). The results were identical regardless which form of gossypol was used, and therefore, they have been combined for presentation in this article. The maximum tolerated dose of gossypol in rats (strain not specified) is reported to be $15-20 \mathrm{mg} / \mathrm{kg} /$ day (Segal, personal communication). This dose induces infertility within 5 weeks. The noeffect dose is reported to be $5 \mathrm{mg} / \mathrm{kg} / \mathrm{day}$. The doses used in this experiment were 5,10 , and $20 \mathrm{mg} / \mathrm{kg}$. A mixture of gossypol in sesame oil containing $0.5 \%$ gum tragacanth was prepared twice each week. The mixture was prepared so that the appropriate dose of gossypol was contained in $0.5 \mathrm{ml}$. Control rats received $0.5 \mathrm{ml}$ of a sesame oil-gum tragacanth mixture.

Received November 9, 1984; accepted May 3, 1985 
Male rats were kept in individual cages, except when breeding. Female rats were kept in groups of five or six until they were bred. For breeding, a male was caged overnight with three females selected at random. The day of finding sperm in the vaginal smear was designated day 0 of pregnancy. Male rats of proven fertility were gavaged, under light ether anesthesia, with either 10 or $20 \mathrm{mg}$ gossypol/kg body weight/day for six consecutive days each week. Males receiving the 20 $\mathrm{mg} / \mathrm{kg}$ dose were treated for 5 weeks. Males receiving the $10-\mathrm{mg} / \mathrm{kg}$ dose were treated for 9 weeks, except for three males who continued to have successful matings, and were treated for 16 weeks. Throughout the experiment, each male was placed with females each week until one successful copulation was achieved. Only occasionally did a male fail to achieve copulation each week (determined by presence of sperm in the vaginal smear). During the period of infertility, the sperm head was frequently separated from the sperm tail. The experiment was continued until each male had recovered his fertility and impregnated four females. Pregnant females were gavaged, under light ether anesthesia, with a dose of either $10 \mathrm{mg}$ or 20 $\mathrm{mg}$ gossypol/kg maternal body weight. Some pregnant rats received a 1-day gavage treatment, on either day $6,8,10,12,14$, or 16 of pregnancy, while others were gavaged daily from day 6 through day 15 . Some rats in the latter group received a dose of $5 \mathrm{mg} / \mathrm{kg}$.

All pregnant rats were kept in individual cages. At day 20 , they were given an overdose of ether, and the uteri were exposed and examined for resorption sites. The fetuses were recovered, weighed, and fixed in Bouin's fluid or $95 \%$ alcohol. In experiments in which the male was treated, the fetuses in each litter were apportioned between Bouin's fluid and alcohol in a ratio of approximately 4:1. In experiments in which the pregnant female was treated, whole litters were fixed in either Bouin's fluid or alcohol in a ratio of approximately 3:2. The fetuses fixed in Bouin's fluid were subsequently examined for external malformations and then free-hand sectioned with a razor blade. Fetuses fixed in alcohol were prepared for staining with alizain red $\mathrm{S}$ for visualization of the skeleton.

Four gossypol-treated males $(20 \mathrm{mg} / \mathrm{kg}$ ) and two sesame oil-treated males were randomly selected to mate with untreated females who were allowed to deliver and rear their pups. There were nine such matings in the gossy. pol group and ten matings in the sesame oil group. Ninety viable pups (11.2/itter) were delivered from the gossypol matings and 115 pups (11.5/litter) from the sesame oil matings, two of which died. Each litter was culled to three male pups and three female pups. The pups in each litter were tested for postnatal maturation according to procedures outlined by Zbinden ('81). The results for fetal weight and resorption were analyzed by the Student t-test for independent samples (Brown and Hollander, '77). Because of the very few numbers of malformations, the incidence was not analyzed statistically.

\section{RESULTS}

A total of 38 males received gossypol, 19 at $20 \mathrm{mg} / \mathrm{kg}, 16$ at $10 \mathrm{mg} / \mathrm{kg}$ (Table 1), and 3 that died from complications resulting from the procedure, not because of the gossypol. Four males (three at the high dose) became sick during treatment (listless, rough coat, anorexic) but recovered completely following cessation of treatment at the end of the experiment. The remaining males appeared healthy throughout the experiment. Twenty males were used as controls and received the sesame oil-gum tragacanth mixture. These males were healthy throughout the experiment. During the period of gossypol treatment, weight gain was very erratic but averaged one-half the weight gained in controls $(P=0.001)$. In the period following treatment, weight gain resumed. At the end of the experiment, some males treated with the high dose of gossypol gained less weight than their control counterparts, but the difference was not statistically significant. There was no difference in weight gain between controls and males treated with the low dose of gossypol.

Gossypol induced infertility in all males treated with the $20-\mathrm{mg} / \mathrm{kg}$ dose, although its onset and duration were variable. Infertile matings were observed as early as the third week of treatment and as late as the last week of treatment (fifth week). With the low dose, infertility began as early as the fourth week and as late as the last week of treatment (ninth week) except that three males continued to have fertile matings even after 16 weeks of gossypol-treatment. The duration of infertility ranged between 3 and 7 weeks (average $=5$ weeks) at the high dose and between 2 and 7 weeks (average $=4.4$ weeks) at the low dose. It must be noted, however, that these figures are not exact be- 
TABLE 1. Gossypol-treated males and the outcome of pregnancy

\begin{tabular}{|c|c|c|c|c|}
\hline Treatment $^{1}$ & $\begin{array}{c}\text { No. } \\
\text { females } \\
\text { pregnant }\end{array}$ & $\begin{array}{c}\text { Fetal } \\
\text { weight }(\mathrm{gm}) \\
(\text { mean } \pm \text { SD) }\end{array}$ & $\begin{array}{c}\text { No. } \\
\text { implantation } \\
\text { sites }\end{array}$ & $\%$ Resorbed $\pm \mathrm{SD}$ \\
\hline \multicolumn{5}{|l|}{ Pretreatment } \\
\hline GP-20 & 21 & $3.65 \pm 0.38$ & 270 & $3.4 \pm 6.0$ \\
\hline Sesame & 11 & $3.58 \pm 0.20$ & 144 & $4.6 \pm 8.3$ \\
\hline GP-10 & 20 & $3.67 \pm 0.30$ & 260 & $5.0 \pm 5.6$ \\
\hline Sesame & 8 & $3.51 \pm 0.21$ & 105 & $5.2 \pm 5.0$ \\
\hline \multicolumn{5}{|c|}{ During treatment } \\
\hline GP-20 & 72 & $3.72 \pm 0.27$ & 920 & $4.2 \pm 3.5$ \\
\hline Sesame & 59 & $3.81 \pm 0.49$ & 783 & $3.9 \pm 4.9$ \\
\hline GP-10 & 83 & $3.64 \pm 0.5$ & 954 & $6.6 \pm 4.8$ \\
\hline Sesame & 37 & $3.52 \pm 0.31$ & 525 & $7.0 \pm 4.2$ \\
\hline \multicolumn{5}{|l|}{ Postreatment } \\
\hline GP-20 & 91 & $3.27 \pm 0.53$ & 1,125 & $6.8 \pm 3.5$ \\
\hline Sesame & 64 & $3.62 \pm 0.40$ & 870 & $5.1 \pm 3.5$ \\
\hline GP-10 & 76 & $3.58 \pm 0.33$ & 937 & $4.5 \pm 3.1$ \\
\hline Sesame & 20 & $3.52 \pm 0.27$ & 270 & $7.0 \pm 4.8$ \\
\hline
\end{tabular}

${ }^{1}$ GP-20, 19 males treated with gossypol $20 \mathrm{mg} / \mathrm{kg} /$ day for 5 weeks; GP-10, 16 males treated with gossypol $10 \mathrm{mg} / \mathrm{kg} / \mathrm{day}$ for 9 -16 weeks; Sesame, 20 males treated with sesame oil (13 for GP-20, 7 for GP-10).

cause, for one reason or another, males occasionally failed to mate during a given week. Sesame oil did not interfere with fertility.

Table 1 summarizes the results of breeding males prior to, during, and following treatment with gossypol. An analysis of the table reveals that gossypol administered to males had no significant effect on day 20 fetal weight, or on the incidence of resorption. The number of resorptions did not increase significantly during or following gossypol treatment, nor did gossypol treatment increase the number of resorptions over the number found with sesame oil treatment. In five of the six groupings, there were more resorptions in the sesame oil groups than in the gossypol groups. The incidence of resorption in Sprague-Dawley untreated rats can be expected to be around $6 \%$ (based on observations of 1,758 litters at a commercial laboratory). There was no difference between the weight of fetuses in the control and experimental groups. There were 1,938 fetuses examined for soft-tissue defects in pregnancies from sesame oil-treated males. Three of these $(0.15 \%)$ were malformed. Ten malformed fetuses were found in 3,206 fetuses examined for soft tissue defects in matings from gossypol-treated males $(0.3 \%)$. The incidence of malformations in untreated Sprague-Dawley rats can be expected to be about $0.5 \%$ (based on observations of 21,186 fetuses at a commercial laboratory). There was no alteration in the sex ratio of the fetuses fol- lowing treatment of the male parent with gossypol.

Table 2 lists the malformations observed. In the gossypol-treated groups, one malformed fetus occurred in a litter from a mating prior to treatment and two malformed fetuses occurred in litters from matings during treatment. The remaining seven malformed fetuses were found in litters from matings after treatment. No single abnormality was common to all malformed fetuses, and no dose response was observed. In the sesame oil-treated matings, all malformations occurred in litters from matings during the treatment period.

The skeleton was examined in fetuses from matings that occurred prior to treatment, during treatment, and following treatment. In the $20-\mathrm{mg} / \mathrm{kg}$ group, a total of 541 fetuses from the experimental matings and $398 \mathrm{fe}$ tuses from the control matings were examined. In the $10-\mathrm{mg} / \mathrm{kg}$ group, a total of 466 fetuses were examined from the experimental matings and 188 fetuses from the control matings. The results did not differ between the two groups. No malformations were induced by gossypol treatment. There were minor differences in the amount of ossification in specific bones between the experimental and control fetuses, but no trend was established and no dose response was demonstrated.

Very few differences were observed in the behavioral tests of the offspring from mat- 
TABLE 2. Gross and soft-tissue malformations in fetuses from matings with gossypol-treated males

\begin{tabular}{|c|c|c|c|c|}
\hline Treatment & $\begin{array}{c}\text { Dosage } \\
(\mathrm{mg} / \mathrm{kg} / \text { day })\end{array}$ & Male No. & Malformation & Time of occurrence \\
\hline \multirow[t]{10}{*}{ Gossypol $^{1}$} & \multirow[t]{3}{*}{20} & 23 & One fetus: hydronephrosis & $\begin{array}{l}7 \text { weeks after cessation } \\
\text { of treatment }\end{array}$ \\
\hline & & 27 & $\begin{array}{l}\text { One fetus: tailless, imperforate } \\
\text { anus, fused kidneys }\end{array}$ & $\begin{array}{l}8 \text { weeks after cessation } \\
\text { of treatment }\end{array}$ \\
\hline & & 32 & $\begin{array}{l}\text { One fetus: right-sided aortic } \\
\text { arches }\end{array}$ & $\begin{array}{l}6 \text { weeks after cessation } \\
\text { of treatment }\end{array}$ \\
\hline & \multirow[t]{7}{*}{10} & 43 & $\begin{array}{l}\text { One fetus: right-sided aortic } \\
\text { arches }\end{array}$ & $\begin{array}{l}8 \text { weeks after cessation } \\
\text { of treatment }\end{array}$ \\
\hline & & 46 & One fetus: gastrochschisis & $\begin{array}{l}3 \text { weeks after cessation } \\
\text { of treatment }\end{array}$ \\
\hline & & \multirow[t]{2}{*}{58} & $\begin{array}{l}\text { One fetus: right-sided aortic } \\
\text { arches }\end{array}$ & 1st week of treatment \\
\hline & & & $\begin{array}{l}\text { One fetus: tailles, imperforate } \\
\text { anus }\end{array}$ & $\begin{array}{l}6 \text { weeks after cessation } \\
\text { of treatment }\end{array}$ \\
\hline & & 60 & One fetus: hydronephrosis & $\begin{array}{l}6 \text { weeks after cessation } \\
\text { of treatment }\end{array}$ \\
\hline & & \multirow[t]{2}{*}{62} & One fetus: hydronephrosis & $\begin{array}{l}1 \text { week before } \\
\text { treatment }\end{array}$ \\
\hline & & & One fetus: hydronephrosis & 3rd week of treatment \\
\hline Sesame oil ${ }^{2}$ & & $\begin{array}{l}28 \\
45 \\
54\end{array}$ & $\begin{array}{l}\text { One fetus: anophthalmia } \\
\text { One fetus: cleft palate } \\
\text { One fetus: microphtalmia }\end{array}$ & $\begin{array}{l}\text { 5th week of treatment } \\
4 \text { th week of treatment } \\
9 \text { th week of treatment }\end{array}$ \\
\hline
\end{tabular}

${ }^{1} 10$ malformed fetuses in 3,206 sectioned fetuses $(0.3 \%)$.

${ }^{2} 3$ malformed fetuses in 1,938 sectioned fetuses $(0.15 \%)$.

ings between untreated females and either gossypol-treated or sesame oil-treated males. The events examined during the first week of postnatal life (righting reflex, pina detachment, negative geotaxis, presence of downy hair, and attainment of the palmar grasp) had little variation between the experimental group and the control group. The events examined during the second week (presence of fur, auditory startle reflex, full eye opening, and the free-fall righting reflex) and the final two events evaluated-descent of the testis and opening of the vagina (during the fifth and sixth postnatal weeks)-showed minor discrepancies between experimental and control pups, but it is probable that age differences at the time of testing accounted for the variation. Deliveries were not always observed, especially at night and during weekends and, therefore, the exact age of the pups was sometimes unknown.

Table 3 summarizes the effects of gossypol when administered to pregnant dams as a single gavage dose during 1 day of pregnancy. The days of treatment were gestation days $6,8,10,12,14$, or 16 . All viable day 20 fetuses were fixed in Bouins' fluid and subsequently sectioned. Neither the $10-\mathrm{mg} / \mathrm{kg}$ dose nor the $20-\mathrm{mg} / \mathrm{kg}$ dose had any adverse effect in the dams. Their pregnancies were uneventful, and the dams remained healthy throughout the experiment. The fetuses were examined for gross and soft tissue malformations only. Gossypol had no significant effect on the number of implantation sites in each litter or on the number of resorptions. Because the highest dose had no effect, very few rats were tested at the low dose. Fetal weight appeared unaffected by gossypol treatment. A possible decrease in fetal weight following $10-\mathrm{mg} / \mathrm{kg}$ dose at day 10 and 16 is indicated in the table. However, only three dams were dosed at each day, and the decreased weight may be spurious. There were very few malformations seen in either the experimental or the control fetuses. Of 1,266 fetuses from gossypol-treated dams examined for gross and soft tissue malformations, only three fetuses were abnormal $(0.2 \%)$. One fetus from a dam treated at day $10 \mathrm{had}$ anophthalmia and cleft palate, one fetus from a dam treated at day 14 had microphthalmia, and another fetus had anophthalmia. Of 648 fetuses examined from sesame oil-treated dams, two were abnormal $(0.3 \%)$. Both abnormal fetuses were found in litters of dams treated with sesame oil at day 12 . One fetus was agnathic and the other had right-sided aortic arches. The incidence of malformations was very low in both experimental and 


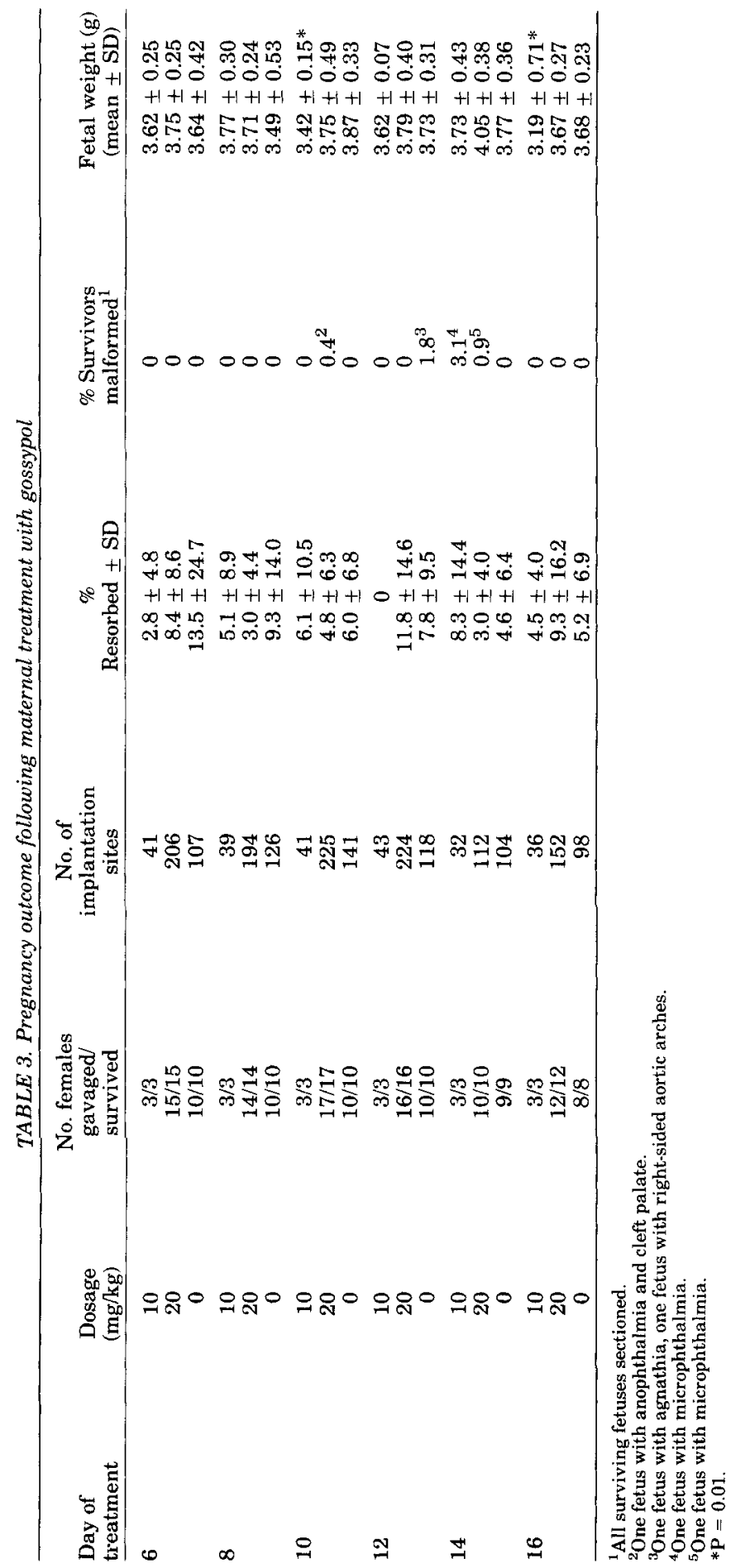


control litters, less than the expected spontaneous incidence for the Sprague-Dawley rat $(0.5 \%)$. No dose response was demonstrated. The skeleton was examined in fetuses from additional dams receiving the single treatment with gossypol or sesame oil. A total of 466 fetuses were examined from 37 sesame oil-treated dams, 646 fetuses from 51 dams treated with $20 \mathrm{mg} / \mathrm{kg}$ gossypol, and $158 \mathrm{fe}$ tuses from 13 dams treated with $10 \mathrm{mg} / \mathrm{kg}$ gossypol. There was no apparent difference in ossification between experimental and control fetuses at any day examined.

Table 4 gives the results of gossypol administration throughout the period of organogenesis (days 6-15). There was no adverse affect of gossypol on the health of the pregnant dam. The incidence of resorption in the 20$\mathrm{mg} / \mathrm{kg}$ group was less than the incidence in the two other gossypol groups, and also less than in the sesame oil control group. The weight of the day 20 fetus was unaffected by gossypol treatment. All 578 viable fetuses from gossypol-treated dams were examined for gross and soft tissue malformations; three were abnormal $(0.5 \%)$. One fetus in the $5-\mathrm{mg} /$ $\mathrm{kg}$ group was agnathic. One fetus in the 20 $\mathrm{mg} / \mathrm{kg}$ group had anopthalmia and micrognathia; and one fetus had anophthalmia, exencephaly, and umbilical hernia. Only one fetus of 325 surviving fetuses of sesame oiltreated dams was abnormal $(0.3 \%)$. The incidence of malformations was very low in both experimental and control fetuses, no higher than the expected spontaneous incidence for the Sprague-Dawley rat. Skeletons of fetuses from additional dams treated daily throughout the organogenetic period were also examined. Sixty fetuses were examined from five sesame oil-treated dams, 66 fetuses from five dams treated with $5 \mathrm{mg} / \mathrm{kg}$ gossypol, 51 from five dams treated with $10 \mathrm{mg} / \mathrm{kg}$, and 84 from six dams treated with $20 \mathrm{mg} / \mathrm{kg}$. There were no apparent differences in skele- tal development between the experimental and control fetuses.

\section{DISCUSSION}

Gossypol can induce both morphological and biochemical alterations in spermatozoa. As long as spermatozoa retain their ability to fertilize, however, there is apparently no adverse affect on the outcome of that fertilization. Based on the results of the present study, it can be concluded that gossypol treatment of male rats does not influence the outcome of pregnancies resulting from conception during the treatment period or after the treatment period. There were no observable effects on fetal weight or on the incidence of resorption and malformation. The results demonstrate that there are individual variations in the response of males to gossypol treatment with respect to the time of onset and the duration of infertility. All males recovered their fertility, however. The antifertility effect of gossypol was obtained without any marked toxicity to the males, in contrast to the report by Weinbauer et al. ('83).

The incidence of malformations was very low in this experiment, lower than expected to occur spontaneously in a colony of untreated Sprague-Dawley rats. Regardless of treatment, there was never more than one malformed fetus in any given litter. Each malformation observed in both experimental and control fetuses has been described as a spontaneous malformation in the SpragueDawley rat. A dose response was not demonstrated, and there was no distinct or reproducible syndrome of malformations. These observations suggest that the malformations are not due to the treatment of males with gossypol.

The effect of gossypol treatment of the female has not been studied extensively. Hahn et al. ('81) found that doses of gossypol up to

TABLE 4. Pregnancy outcome following maternal treatment with gossypol

\begin{tabular}{|c|c|c|c|c|c|c|}
\hline $\begin{array}{l}\text { Day of } \\
\text { treatment }\end{array}$ & $\begin{array}{r}\text { Dosage } \\
(\mathrm{mg} / \mathrm{kg})\end{array}$ & $\begin{array}{c}\text { No. females } \\
\text { injected/survived }\end{array}$ & $\begin{array}{c}\text { No. } \\
\text { implantation } \\
\text { sites }\end{array}$ & $\begin{array}{c}\text { \% Resorbed } \\
\pm \mathrm{SD}\end{array}$ & $\begin{array}{l}\% \text { Survivors } \\
\text { malformed }^{1}\end{array}$ & $\begin{array}{l}\text { Fetal weight }(\mathrm{gm}) \\
(\text { mean } \pm \mathrm{SD})\end{array}$ \\
\hline $6-15$ & $\begin{array}{r}5 \\
10 \\
20 \\
0\end{array}$ & $\begin{array}{l}15 / 15 \\
15 / 15 \\
15 / 15 \\
24 / 24\end{array}$ & $\begin{array}{l}213 \\
213 \\
188 \\
342\end{array}$ & $\begin{array}{l}6.8 \pm 5.0 \\
6.3 \pm 5.7 \\
3.7 \pm 6.0 \\
5.0 \pm 5.1\end{array}$ & $\begin{array}{l}0.5^{2} \\
0 \\
1.1^{3} \\
0.3^{4}\end{array}$ & $\begin{array}{l}3.48 \pm 0.67 \\
3.83 \pm 0.26 \\
3.65 \pm 0.30 \\
3.71 \pm 0.30\end{array}$ \\
\hline
\end{tabular}

${ }^{1}$ All surviving fetuses sectioned.

${ }^{2}$ One fetus with agnathia.

${ }^{3}$ One fetus with anophthalmia and micrognathia; one fetus with anophthalmia, exencephaly, and umbilical hernia

${ }^{4}$ One fetus with umbilical hernia. 
$80 \mathrm{mg} / \mathrm{kg}$ administered for the three consecutive days prior to ovulation had no effect on ovulation in the rat. They also reported that treatment of pregnant mice from day 1 to 13 of pregnancy resulted in increased numbers of nonviable fetuses. However, the authors raised serious questions about the unhealthy conditions of the mice used in their experiment. Wu et al. ('81) examined gossypoltreated hamsters for effects on endocrine function, ovulation, and fertility. They reported a rise in serum follicle-stimulating hormone (FSH), a fall in pituitary FSH, and a higher serum and ovarian concentration of estrone and estradiol in gossypol-treated hamsters compared with controls. The estrous cycle remained normal, and there was no effect on ovulation. Wu et al. ('81) reported that gossypol failed to alter the pregnancy rate or affect the outcome of pregnancy: all fetuses appeared normal, with no retardation of growth. However, only five pregnant hamsters were examined.

In the present experiment, gossypol administered to pregnant dams, either on a single day during gestation or throughout the organogenetic period, had little observable effect on the outcome of pregnancy. There was no effect on fetal weight at day 20 of gestation, and there was no increase in resorptions. Maturation of the pups during the first month of postnatal life was unaffected by gossypol treatment. Examination of the fetal skeleton revealed no significant difference between experimental and control fetuses. The incidence of malformations was lower in this experiment than the spontaneous incidence expected in a colony of Sprague-Dawley rats $(0.5 \%)$. This observation, together with the lack of a demonstrable dose response, and the lack of a distinct or reproducible syndrome of malformations, strongly favors the conclusion that gossypol is not teratogenic in the pregnant rat.

Under the conditions of these experiments, gossypol administered to either the breeding male rat or the pregnant female rat had no significant adverse effect on the outcome of conception.

\section{ACKNOWLEDGMENTS}

This research was supported by a grant from The Rockefeller Foundation.

\section{LITERATURE CITED}

Bozek, S.A., D.R. Jensen, and J.M. Tone (1981) Scanning electron microscopic study of spermatozoa from gossypol-treated rats. Cell Tissue Res., 219:659-663.
Brown, W.B., and M. Hollander (1977) Statistics. A Biomedical Introduction. John Wiley \& Sons, New York.

Chang, M.C., Z. Gu, and S.K. Saksena (1980) Effect of gossypol on the fertility of male rats, hamsters and rabbits. Contraception, 21:461-469.

Hadley, M.A., Y.C. Lin, and M. Dym (1981) Effect of gossypol on the reproductive system of male rats. J. Androl., 2:190-199.

Hahn, D.W., C. Rusticus, A. Probst, R. Homm, and A.N. Johnson (1981) Antifertility and endocrine activities of gossypol in rodents. Contraception, 24:97-105.

Hoffer, A.P. (1982) Ultrastructural studies of spermatozoa and the epithelial lining of the epididymis and vas deferens in rats treated with gossypol. Arch. Androl. 8:233-246.

Kalla, N.R., and M. Vasudev (1981) Studies on the male antifertility agent-gossypol acetic acid: II. Effect of gossypol acetic acid on the motility and ATPase activity of human spermatozoa. Andrologia, 13:95-98.

Ke, Y.-B., and W.-W. Tso (1982) Variations of gossypol susceptibility in rat spermatozoa during spermatogenesis. Int. J. Fertil., 27:42-46.

Kennedy, W.P., H.H. Vand der Ven, J.W. Straus, A.K Bhattacharyya, D.P. Waller, L.J.D. Zanevels, and K.L Polakoski (1983) Gossypol inhibition of acrosin and proacrosin, and oocyte penetration by human spermatozoa. Biol. Reprod., 29:999-1010.

Lee, C.Y.G., Y.S. Moon, J.H. Yuan, and A.F. Chen (1982) Enzyme inactivation and inhibition by gossypol. Mol. Cell Biochem., 47:65-70.

Lin, T., E.P. Murono, J. Osterman, H.R. Nankin, and P.B. Coulson (1981) Gossypol inhibits testicular steroidogenesis. Fertil. Steril., 35:563-566.

National Coordinating Group on Male Antifertility Agents (1978) Gossypol, a new antifertility agent for males. Chinese Med. J., 4:417-428.

Oko, R., and F. Hrudka (1982) Segmental aplasia of the mitochondrial sheath and sequelae induced by gossypol in rat spermatozoa. Biol. Reprod., 26:183-196.

Pons, W.A., J. Pominski, W.H. King, J.A. Harris, and T.H. Hopper (1959) Recovery of gossypol from cottonseed gums. J. Am. Oil Chemists Soc., 36:328-332.

Saksena, S.K., R. Salmonsen, I.F. Lau, and M.C. Chang (1981) Gossypol: Its toxicological and endocrinological effects in male rabbits. Contraception, 24:203-214.

Saksena, S.K., and R.A. Salmonsen (1982) Antifertility effect of gossypol in male hamsters. Fertil. Steril., 37:686-690.

Shandilya, L., T.B. Clarkson, M.R. Adams, and J.C. Lewis (1982) Effects of gossypol on reproductive and endocrine functions of male cynomolgus monkeys (MacacaFascicularis). Biol. Reprod. 27:241-252.

Tso, W.-W., and C.-S. Lee (1982) Gossypol: An effective acrosin blocker. Arch. Androl, 8:143-148.

Tso, W.-W., C.-S. Lee, and M.-Y. Tso (1982) Effect of gossypol on boar spermatozoal adenosine triphosphate metabolism. Arch. Adnrol., 9:319-332.

Weinbauer, G.F., E. Rovan, and J. Frick (1982) Antifertility efficacy of gossypol acetic acid in male rats. Andrologia, 14:270-275.

Weinbauer, G.F., E. Rovan, and J. Frick (1983) Toxicity of gossypol at antifertility dosages in male rats: Statistical analysis of lethal rates and body weight responses. Andrologia, 15:213-221.

Wu, Y.M., S.C. Chappel, and G.L. Flinckinger (1981) Effects of gossypol on pituitary-ovarian endocrine function, ovulation and fertility in female hamsters. Contraception, $24: 259-268$.

Zbinden, G. (1981) Experimental methods in behavioral teratology. Arch. Toxicol., 48:69-88. 